\title{
Isolamento de microrganismos e estudo da produção de lipase utilizando resíduos agroindustriais
}

Isolation of microorganisms and lipase production study using agricultural residues

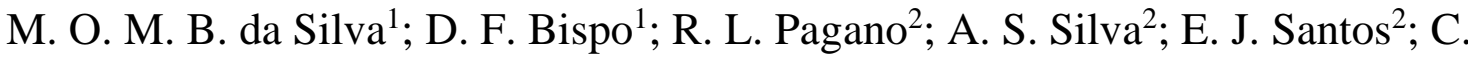 \\ F. Silva ${ }^{2 *}$ \\ ${ }^{1}$ Departamento de Engenharia Química, Universidade Federal de Sergipe, CEP 49100-000, São Cristóvão- \\ SERGIPE, Brasil \\ ${ }^{2}$ Programa de Pós Graduação em Engenharia Química, Universidade Federal de Sergipe, CEP 49100-000, São \\ Cristóvão-SERGIPE, Brasil
}

*ferrazcristina@ufs.br

(Recebido em 15 de março de 2016; aceito em 28 de abril de 2016)

\begin{abstract}
Lipases são enzimas que vêm se destacando no cenário da biotecnologia, principalmente devido a sua capacidade em catalisar reações de hidrólise e de síntese. As lipases são produzidas tanto por microrganismos, como por organismos animais e vegetais, porém as de origem microbiana são atualmente as mais utilizadas industrialmente. Dentre os microrganismos produtores de lipases estão os fungos filamentosos, as bactérias e as leveduras. O presente trabalho objetivou o isolamento e seleção de bactérias produtoras de lipase, bem como o estudo da produção da enzima usando resíduos provenientes da agroindústria. As amostras para o isolamento foram coletadas em uma planta piloto de biodiesel. Os microrganismos foram isolados e posteriormente submetidos a testes de detecção da atividade lipásica. Após o processo de seleção, os isolados que apresentaram maior índice enzimático (IE), foram utilizados para o estudo da produção de lipase utilizando bagaço de cana-de-açúcar e bagaço de mandioca. Nesse estudo foram isolados 16 microrganismos, sendo que $75 \%$ apresentaram atividade lipolítica. Dentre os isolados selecionados como produtores de lipase, a máxima produção foi atingida com a cepa 8A quando utilizado o bagaço de mandioca durante $48 \mathrm{~h}$ de fermentação.
\end{abstract}

Palavras-chave: Lipase, Microrganismo, Isolamento.

Lipases are enzymes that have been highlighted in the biotechnology scenario, mainly due to their ability to catalyze hydrolysis and synthesis reactions. Lipases are produced by microorganisms, animals and plants, but the microbial origin is currently the most widely used industrially. Among the lipase producers microorganisms are filamentous fungi, bacteria and yeasts. This study aimed to isolation and selection of bacteria producing lipase and the enzyme production study using agro industrial wastes. Samples for isolation were collected in a biodiesel pilot plant. Microorganisms were isolated and then subjected to testing for lipase activity. After the selection process, the isolates showed greater enzymatic index (EI) were used for the study of lipase production using bagasse from sugarcane and cassava bagasse. In this studied were isolated 16 microorganisms, where $75 \%$ presented lipolytic activity. Among the isolates selected as lipase producers, the maximum production was achieved with the $8 \mathrm{~A}$ strain when used bagasse cassava for $48 \mathrm{~h}$ fermentation.

Keywords: Lipase, Microorganism, Isolation.

\section{INTRODUÇÃO}

Lipases (EC 3.1.1.3) são enzimas que vêm se destacando no cenário da biotecnologia, principalmente devido a sua capacidade de catalisar reações de hidrólise e de síntese. As lipases, triacilglicerol éster hidrolase, são enzimas hidrolíticas que "in vivo" catalisam a hidrólise de triacilgliceróis de cadeia longa (acima de 10 átomos de carbono), sendo a trioleína o seu substrato padrão, aos ácidos graxos correspondentes e glicerol, constituindo uma classe especial de carboxil éster hidrolases [1]. A capacidade das lipases em catalisar tanto a hidrólise de 
ésteres, quanto as reações de esterificação e transesterificação, em meio aquoso ou não, permite que estas enzimas sejam utilizadas na síntese regiosseletiva ou na resolução estereoseletiva de álcoois, ácidos carboxílicos e aminas [2,3].

Devido à capacidade catalítica das lipases, essas são excelentes alternativas para as sínteses químicas clássicas, com aplicação nas indústrias de alimentos, detergentes, oleoquímica, farmacêutica, química fina, cosméticos, couro, tratamento de efluentes e na produção de biocombustível [4]. Na manufatura de alimentos são empregadas para a obtenção de ácidos graxos livres por hidrólise seletiva dos óleos e gorduras presentes em diversos alimentos. $\mathrm{Na}$ fabricação de pães são empregadas para melhorar a textura da massa. O emprego de lipase na formulação de detergentes é responsável pela facilidade de unirem-se as gorduras e óleos. Nas indústrias oleoquímicas seu emprego reduz gastos com energia e minimiza a degradação térmica dos compostos em comparação às vias químicas tradicionais. Na indústria farmacêutica as lipases são utilizadas na produção de antidepressivos, anti-hipertensivos e vasodilatadores. As lipases também podem ser utilizadas no tratamento de efluentes e na produção de biodiesel, sendo esta uma das áreas de aplicação que mais crescem nos últimos anos [5]. Na produção de biodiesel, a catálise enzimática abole a necessidade de neutralização e lavagem do biodiesel, além de facilitar a recuperação da glicerina [6,7].

As lipases podem ser produzidas por microrganismos, por animais e por vegetais, porém as lipases de origem microbianas são atualmente as mais utilizadas industrialmente [8,9]. A produção e aplicação de lipases de origem microbiana também tem sido a mais empregada no meio biotecnológico. Esse fato se deve principalmente às facilidades de controle e de aumento da capacidade produtiva dos processos fermentativos, além da redução do custo de obtenção. Em geral, os microrganismos mais utilizados para a produção de lipases são fungos dos gêneros Rhizopus, Aspergillus e Mucor e leveduras do gênero Candida [10]. Dentre as bactérias produtoras de lipase, destacam-se os gêneros Bacillus, Pseudomonas e Burkholderia. As lipases bacterianas apresentam a vantagem de serem excretadas da célula e de poderem ser produzidas por fermentação submersa ou em estado sólido $[11,12,13]$.

A composição do meio de cultivo deve fornecer nutrientes necessários ao crescimento do microrganismo, bem como a produção de compostos metabólitos adequados para suprir a energia para biossíntese e manutenção celular [14]. Contudo, o meio de cultivo é um dos componentes mais relevantes nos custos de produção, por isso, é crescente o interesse no aproveitamento de resíduos lignocelulósicos agroindustriais e florestais como matérias-primas em processos biotecnológicos. Dentre os resíduos destacam-se o farelo de arroz, a torta de canade-açúcar, de mamona e palha. Além disso, o processo também possibilita uma destinação alternativa para esses resíduos e, em alguns casos, uma fonte de renda alternativa para a agricultura familiar.

Assim como qualquer atividade enzimática, a atividade lipolítica pode ser determinada direta ou indiretamente, pelo consumo do substrato ou pela formação de produtos, ou seja, pela liberação de ácidos graxos [15]. Geralmente a atividade da lipase é determinada pela dosagem do produto formado durante um tempo de incubação definido da enzima com o substrato.

O presente trabalho realizou o isolamento de microrganismos e o estudo dos mesmos quanto à capacidade de produção de lipases utilizando resíduos agroindustriais, visando o uso dessas enzimas para a produção de biodiesel e aplicação nas mais diversas áreas biotecnológicas.

\section{MATERIAIS E MÉTODOS}

\subsection{Isolamento e seleção de microrganismos}

\section{Coleta de amostras}

As coletas foram realizadas em planta piloto de biodiesel, localizada no Laboratório de Tecnologia Alternativas (LTA) da UFS (Figura 1). A planta experimental foi mapeada com relação aos pontos mais suscetíveis ao desenvolvimento de microrganismos e, com a ajuda de 
swabs, foram retiradas as amostras. As amostras foram incubadas em Peptona Bacteriológica (1 $\mathrm{g} / \mathrm{L})$ a $30^{\circ} \mathrm{C}$ por $24 \mathrm{~h}$.

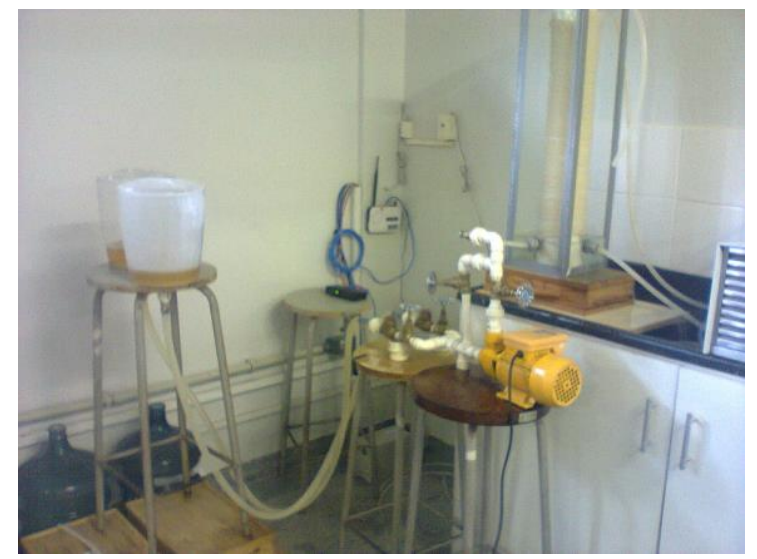

Figura 1: Fotografia da planta piloto de biodiesel instalada no Laboratório de Energias Alternativas (LTA) da UFS. Fonte: arquivo pessoal do autor.

\section{Isolamento}

O isolamento dos microrganismos foi realizado através de semeadura por esgotamento de uma alçada do caldo contendo as amostras em placas de Petri contendo meio Ágar Nutriente. Depois de semeadas, as placas foram incubadas a $30^{\circ} \mathrm{C}$. Os isolados obtidos foram mantidos em tubos contendo Ágar Nutriente inclinado e mantidos a $10^{\circ} \mathrm{C}$.

\section{Seleção de microrganismos produtores de lipase}

O ensaio para detecção da atividade lipolítica dos isolados foi realizado através do método Cup Plate, descrito por Dingle et al. [16] com algumas modificações. Placas de Petri contendo o meio composto por ágar-ágar $(18 \mathrm{~g} / \mathrm{L})$, azeite de oliva $(10 \mathrm{~g} / \mathrm{L})$ e tween $80(1 \mathrm{~g} / \mathrm{L})$ e rodamina $\mathrm{B}$ (2\%) foram utilizadas para inocular as cepas obtidas no isolamento. Após a inoculação, as placas foram incubadas a $30^{\circ} \mathrm{C}$ por 24 e $48 \mathrm{~h}$. A capacidade de produção de enzimas lipases foi determinada através da análise das placas em transiluminador UV. O resultado positivo foi observado por meio da formação de halo fluorescente ao redor do ponto de semeadura do microrganismo. O halo e o crescimento microbiano formados (Figura 2) foram medidos $(\mathrm{cm}) \mathrm{e}$ o Índice Enzimático (IE) foi calculado.

\section{Cálculo do Índice Enzimático}

A atividade enzimática foi determinada pelo método de Hankin e Anagnostakis [17] através da relação entre o diâmetro médio do halo de degradação e o diâmetro médio da colônia, expresso como Índice Enzimático (IE), conforme expresso pela Equação 1.

$$
\mathrm{IE}=\mathrm{D}^{\mathrm{H}} / \mathrm{D}^{\mathrm{CM}} \quad \mathrm{Eq} 1
$$

Onde:

$\mathrm{D}^{\mathrm{H}}=$ Diâmetro Médio do Halo de Degradação

$\mathrm{C}^{\mathrm{CM}}=$ Diâmetro Médio de Crescimento Microbiano 


\subsection{Produção de lipase utilizando resíduos agroindustriais}

Os microrganismos com maior IE foram avaliados quanto à produção de lipase em resíduos agroindustriais. O inóculo dos isolados selecionados foi preparado através da adição de uma alçada da cepa em um tubo de ensaio contendo $5 \mathrm{ml}$ de solução de peptona bacteriológica a $10 \%$ $(\mathrm{m} / \mathrm{v})$. Os tubos foram incubados a $30^{\circ} \mathrm{C}$ durante $24 \mathrm{~h}$ e após, $1 \mathrm{~mL}$ da solução foi passado para um erlenmeyer de $125 \mathrm{~mL}$ contendo $50 \mathrm{~mL}$ de meio peptona bacteriológica a $10 \%(\mathrm{~m} / \mathrm{v})$. O erlenmeyer também foi incubado a $30^{\circ} \mathrm{C}$ em shaker até que os isolados selecionados atingissem $10^{7}$ células $/ \mathrm{mL}$. Em seguida, $5 \mathrm{~mL}$ do inóculo foi adicionado ao meio de produção.

\section{Fermentação em estado sólido}

Os resíduos agroindustriais utilizados para o estudo da produção de lipase pelos isolados selecionados foram o bagaço de cana-de-açúcar (Saccharum officinarum) e bagaço de mandioca (Manihot esculenta). Após secos, homogeneizados e padronizados em tamanho entre 0,5 a 2 mm. $10 \mathrm{~g}$ do resíduo sólido foi colocado em erlenmeyer de $250 \mathrm{~mL}$ e adicionada uma solução tampão fosfato $0,1 \mathrm{~mol} / \mathrm{L} \mathrm{pH} \mathrm{7,0,} \mathrm{de} \mathrm{modo} \mathrm{a} \mathrm{obter} 55 \%$ de umidade. Em seguida, ao mesmo erlenmeyer foi adicionado $1 \%(\mathrm{~m} / \mathrm{v})$ de azeite de oliva. O erlenmeyer foi autoclavado e posteriormente inoculado com $5 \mathrm{~mL}$ do inóculo. Os frascos foram incubados a $30^{\circ} \mathrm{C}$ e as amostras foram retiradas em tempos de 24,48 e $72 \mathrm{~h}$ para extração da enzima e determinação da atividade lipolítica.

\section{Extração da enzima e determinação da atividade lipolítica}

A enzima foi extraída através da adição de $50 \mathrm{~mL}$ de uma solução de $\mathrm{NaCl}(2 \%)$ ao fermentado sólido, seguida de agitação em shaker a $200 \mathrm{rpm}$ durante $1 \mathrm{~h}$ e centrifugação a 4200 rpm durante $15 \mathrm{~min}$. O sobrenadante bruto contendo a enzima foi usado para as análises posteriores. A atividade lipolítica foi determinada usando o método do p-nitrofenol (p-NP), tendo o p-nitrofenil palmitato (p-NPP) como substrato [18]. A emulsão contendo o substrato foi preparada pela adição de $1 \mathrm{~mL}$ de solução de p-NPP em isopropanol a $3 \mathrm{~g} / \mathrm{mL}$ (solução A), seguido da adição de $10 \mathrm{~mL}$ de uma solução contendo $3 \mathrm{~g}$ de Tween 80 dissolvidos em $450 \mathrm{~mL}$ de solução tampão fosfato $\mathrm{pH} 8$ (solução B). $2,7 \mathrm{~mL}$ dessa solução foram incubados até o equilíbrio térmico de $37{ }^{\circ} \mathrm{C}$. Após atingir o equilíbrio, foram adicionados $0,3 \mathrm{~mL}$ de solução enzimática ao sistema e as absorbâncias foram medidas em espectrofotômetro a $410 \mathrm{~nm}$ em intervalos de $30 \mathrm{~s}$ durante $5 \mathrm{~min}$ de reação. Para a determinação da atividade lipolítica, foi calculada a concentração molar de p-NP de acordo com a Equação 2.

$$
\mathrm{C}=\mathrm{A} / \xi \cdot \mathrm{b} \quad \mathrm{Eq} 2
$$

Onde: $\mathrm{C}=$ Concentração Molar de p-NP; A= Absorbância à 410nm; $\xi=$ Coeficiente de Extinção Molar do p-NP (18,5 mL/mol.cm); b= Caminho Óptico $(1 \mathrm{~cm})$

\section{RESULTADOS E DISCUSSÃO}

\section{Isolamento e caracterização dos microrganismos}

A planta experimental de biodiesel foi mapeada em 12 pontos de coleta, sendo considerados os pontos de maior contaminação, apresentando maior probabilidade de obtenção de microrganismos com potencial produção de enzimas lípases. Os pontos identificados como $4 \mathrm{e}$ 10 foram semeados e após o tempo de incubação, não foi observado o desenvolvimento de microrganismos, sendo esses pontos descartados na etapa do isolamento. Ao total foram isoladas 16 cepas bacterianas. Após as análises micro e macroscópica das colônias isoladas, as características morfo-fisiológicas são apresentadas na Tabela 1. 
Tabela 1: Características morfológicas das colônias obtidas.

\begin{tabular}{cccc}
\hline \multirow{2}{*}{ Pontos de Coleta } & $\mathbf{N}^{\mathbf{0}}$ Colônias & \multicolumn{2}{c}{ Características macroscópicas } \\
${ } }$ & 2 & $\begin{array}{c}\text { Colônia a } \\
\text { Amarela, borda definida, } \\
\text { textura gelatinosa } \\
\text { Branca, borda definida, } \\
\text { textura cremosa }\end{array}$ & $\begin{array}{c}\text { Branca, textura cremosa } \\
\text { Amarela, borda definida, } \\
\text { textura cremosa } \\
\text { Amarela, borda circular } \\
\text { Branca, borda definida, } \\
\text { textura cremosa }\end{array}$ \\
$\mathbf{3}$ & 2 & Branca, textura gelatinosa $^{*}$ & - \\
$\mathbf{5}$ & 2 & Branca, borda circular, & - \\
$\mathbf{6}$ & 2 & textura cremosa & - \\
$\mathbf{7}$ & 1 & $\begin{array}{c}\text { Branca, aparência porosa } \\
\text { Branca, textura cremosa } \\
\text { Branca, borda circular, } \\
\text { tamanho pequeno }\end{array}$ & Branca, borda circular, \\
$\mathbf{8}$ & 1 & tamanho grande \\
$\mathbf{9}$ & 1 & Amarela, textura gelatinosa & - \\
$\mathbf{1 1}$ & 2 & Branca, borda definida, \\
leve cheiro adocicado & - \\
$\mathbf{1 2}$ & 1 & & \\
\hline
\end{tabular}

*ND: Não Determinado

\section{Ensaio qualitativo para detecção de lipase (Método Cup-Plate)}

A atividade lipolítica em meio sólido contendo o substrato específico foi detectada através da formação de halo quando os corantes reagiram com os ácidos graxos liberados, indicando a produção de enzima lipase no meio [15]. A coloração alaranjada fluorescente verificada na Figura 2 foi adquirida devido à formação de complexos oriundos da reação dos ácidos graxos, resultantes da hidrólise promovida pela ação da lipase, com a rodamina B presente no meio de cultura [19].

Dezesseis cepas foram testadas quanto à produção de lipase, dentre essas, doze cepas $(75 \%$ dos isolados) apresentaram resultados positivos. Das 12 cepas que apresentaram resultado positivo para produção de enzimas lipases, quatro cepas (2B, 7A, 8A e 11A) apresentaram os maiores valores de Índice Enzimático (IE\%), como pode ser observado na Tabela 2.

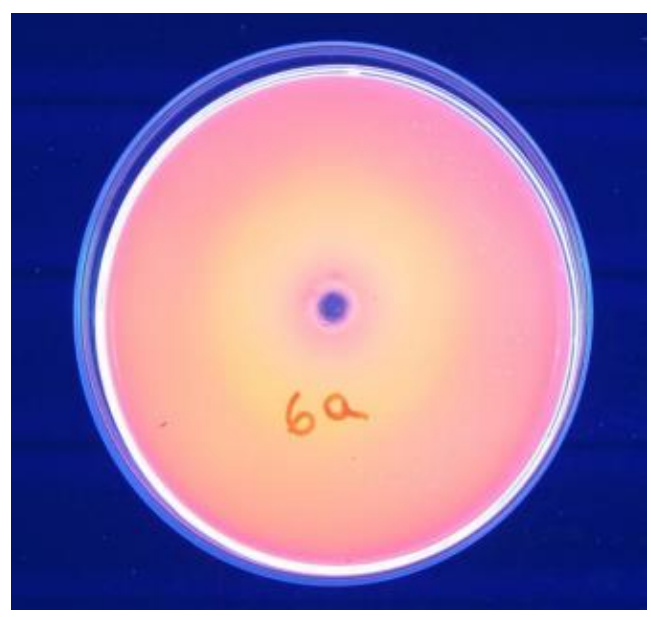

Figura 2: Revelação em luz UV. Fonte: arquivo pessoal do autor. 
Tabela 2: Medida dos halos observados na determinação da atividade lipolítica pelo método Cup-Plate.

\begin{tabular}{cccc}
\hline Amostra & $\begin{array}{c}\text { Diâmetro } \\
\text { Halo }(\mathbf{c m})\end{array}$ & $\begin{array}{c}\text { Diâmetro } \\
\text { Colônia }(\mathbf{c m})\end{array}$ & $\begin{array}{c}\text { Índice Enzimático } \\
(\text { IE\% })\end{array}$ \\
\hline $1^{\mathrm{a}}$ & 6,80 & 3,40 & 2,00 \\
$1 \mathrm{~B}$ & $* \mathrm{ND}$ & $* \mathrm{ND}$ & - \\
$2^{\mathrm{a}}$ & $* \mathrm{ND}$ & $* \mathrm{ND}$ & - \\
$2 \mathrm{~B}$ & 9,50 & 4,00 & 2,37 \\
$3^{\mathrm{a}}$ & 5,80 & 2,90 & 2,00 \\
$3 \mathrm{~B}$ & $* \mathrm{ND}$ & $* \mathrm{ND}$ & - \\
$5 \mathrm{~A} 1$ & 5,00 & 2,50 & 2,00 \\
$5 \mathrm{~A} 2$ & 6,90 & 3,45 & 2,00 \\
$5 \mathrm{~B}$ & 6,40 & 6,20 & 1,03 \\
$6^{\mathrm{a}}$ & 5,55 & 2,75 & 1,82 \\
$7^{\mathrm{a}}$ & 10,00 & 4,25 & 2,35 \\
$8^{\mathrm{a}}$ & 10,50 & 4,50 & 2,34 \\
$9^{\mathrm{a}}$ & 4,70 & 2,35 & 2,00 \\
$9 \mathrm{~B}$ & 4,80 & 2,40 & 2,00 \\
$11^{\mathrm{a}}$ & 8,10 & 3,55 & 2,28 \\
$12^{\mathrm{a}}$ & $* \mathrm{ND}$ & $* \mathrm{ND}$ & - \\
\hline
\end{tabular}

Estudos realizados por Bhavani et al. [20] verificaram que a temperatura e o período de incubação dos microrganismos isolados compreendem fatores importantes que influenciam na produção de lípase e consequentemente na atividade lipolítica.

\section{Fermentação em estado sólido e quantificação da atividade lipolítica}

As cepas selecionadas como melhores produtoras de enzimas lipolíticas, 2B, 7A, 8A e 11A, foram utilizadas nos testes de produção de lipases por fermentação em estado sólido, tendo como substratos os resíduos agroindustriais, bagaço de cana-de-açúcar e de mandioca, e como indutor o óleo de oliva.

Os indutores utilizados na produção de lipases compreendem diferentes óleos vegetais, tais como babaçu, girassol, oliva, soja, palma, canola, milho, bem como gorduras animais [21]. Dos indutores citados, o óleo de oliva é o mais empregado, possivelmente devido à maior porcentagem de trioleína em sua composição, a qual compreende o substrato natural para as enzimas lipases [1].

Falony et al. [22] realizou o estudo de produção de lipase com Aspergillus niger em diversos óleos, como o de girassol, algodão e oliva, obtendo como melhor resultado a produção em presença de óleo de oliva. Assim como em estudos realizados por Kumar et al. [23], que testou diversos óleos e obteve maior atividade lipolítica em meio contendo óleo de oliva.

A atividade lipolítica do extrato enzimático bruto (sem tratamento prévio) foi determinada segundo o método da hidrólise do pNPP. As Figuras 3 e 4 mostram as concentrações molares (CM) do p-NP produzido em $24 \mathrm{~h}, 48 \mathrm{~h}$ e $72 \mathrm{~h}$ nos diferentes substratos. Os valores descritos nas Figuras 3 e 4 descrevem a concentração de $p$-nitrofenol liberado na reação de hidrólise do palmitato de $p$-nitrofenila, estando esses dados diretamente relacionados com a atividade de lipases produzidas no meio.

Como pode ser observado na Figura 3, a maior atividade foi obtida com a cepa $11 \mathrm{~A}$ no tempo de $72 \mathrm{~h}$ com concentração molar do p-NP de $1,87 \times 10^{-2}$ quando utilizado o bagaço de cana-de-açúcar. Já o isolado 8A apresentou uma produção semelhante (concentração molar p$\mathrm{NP}$ de $1,76 \times 10^{-2}$ ) no mesmo substrato em $24 \mathrm{~h}$, tornando esta possivelmente mais viável, visto que o tempo de reação é menor. 
No bagaço de mandioca, a cepa $8 \mathrm{~A}$ também apresentou a maior atividade enzimática em $48 \mathrm{~h}$ de fermentação, alcançando uma concentração molar de p-NP próxima de $5,5 \times 10^{-2}$. No resíduo de mandioca foi observado um aumento da atividade lipolítica de todas as cepas selecionadas, demonstrando o potencial do bagaço de mandioca como substrato biotecnológico.

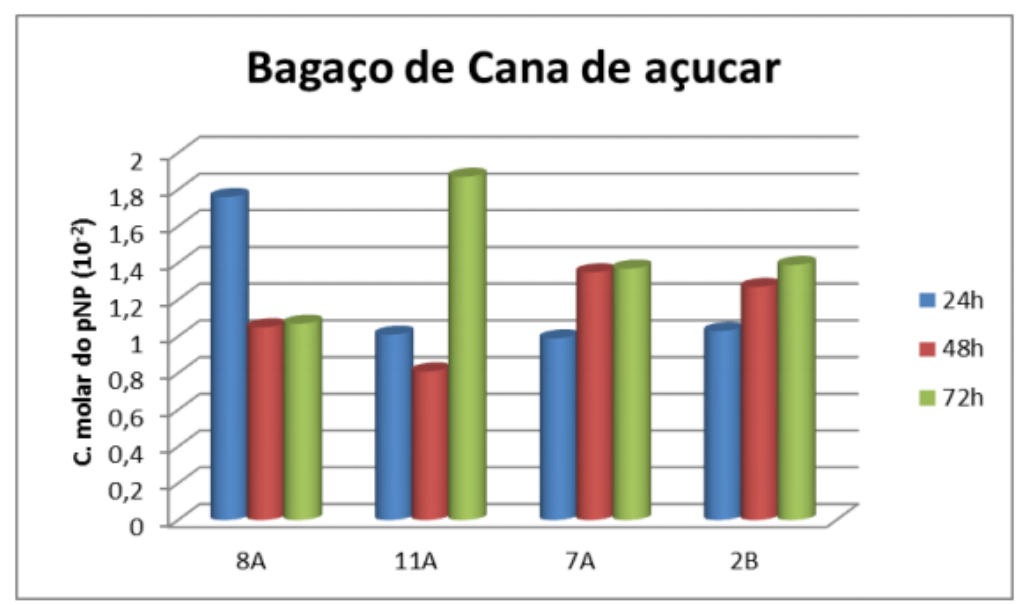

Figura 3: Concentração molar do p-NP em bagaço de cana-de-açúcar.

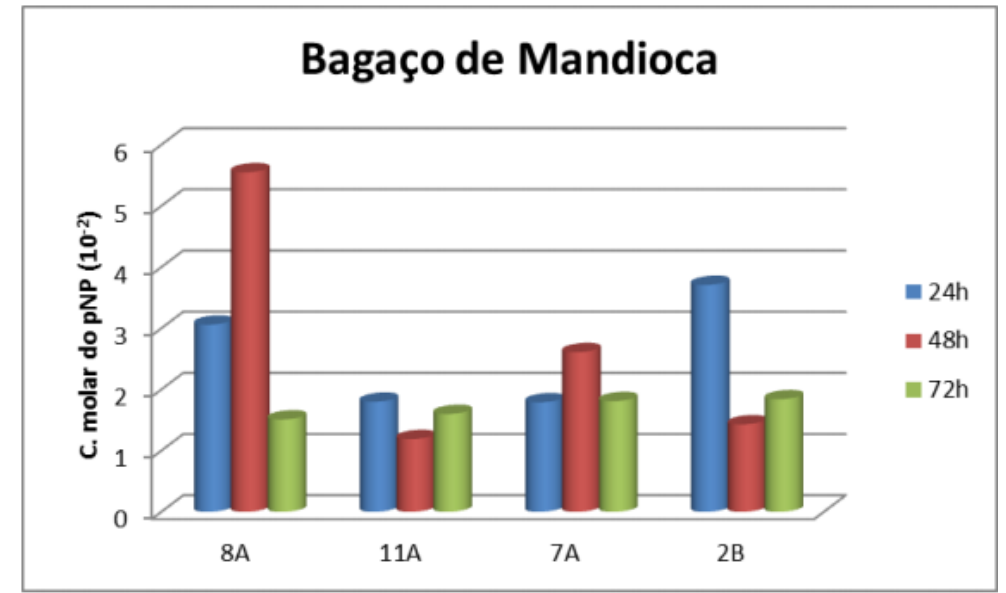

Figura 4: Concentração molar do p-NP em bagaço de mandioca.

\section{CONCLUSÃO}

A coleta de amostras em uma planta de biodiesel foi bem sucedida, dos 12 pontos selecionados apenas dois não apresentaram desenvolvimento de microrganismos. Totalizando 16 isolados.

O método Cup-Plate mostrou-se eficiente e prático na seleção de linhagens produtoras de lipase. Dessa forma, as cepas foram testadas e 12 demostraram atividade lipolítica, o que corresponde a $75 \%$ dos isolados.

A cepa 8A apresentou os melhores valores de concentração de produto (p-NP), onde a concentração molar foi de $1,76 \times 10^{-2}$ em $24 \mathrm{~h}$ de fermentação e de $5,55 \times 10^{-2} \mathrm{em} 48 \mathrm{~h}$ de fermentação quando usado o bagaço de cana e o bagaço de mandioca, respectivamente.

O custo de produção de lipases é atualmente uma das maiores limitações do uso dessas enzimas em processos industriais. Com isso, na tentativa de propor uma possível redução nos 
custos de produção da enzima, os resíduos agroindustriais servem como substratos biotecnológicos potenciais, além de servir como uma alternativa de destinação industrial para os mesmos.

\section{AGRADECIMENTOS}

Os autores agradecem à Universidade Federal de Sergipe e ao Programa de Iniciação Científica (PIIC) pela concessão da bolsa e ao Laboratório de Tecnologias Alternativas (LTA) pela disponibilidade em ceder as amostras para isolamento.

\section{REFERÊNCIAS BIBLIOGRÁFICAS}

1. Fernandes MLM. Produção de lipases por fermentação no estado sólido e sua utilização em Biocatálise [Dissertação]. Curitiba (PR): Universidade Federal do Paraná em Curitiba; 2007. 131p.

2. Duan G, Ching CB, Lin E, Ang CH. Kinetic study of enantioselective esterification of ketoprofen with n-propannol catalyzed by lipase in an organic medium. Biotechnol Lett. 1997 Nov;19(11):1051-5, doi: 10.1023/A:1018420022398

3. Marshall JA, Chobanian H. Lipase-catalyzed resolution of 4-trimethylsilyl-3-butyn-2-ol and conversion of the (r)-enantiomer to (r)-3-butyn-2-yl mesylate and (p)-1-tributylstannyl-1,2-butadiene. Org Synth. 2005 Feb;82:43-54, doi: 10.15227/orgsyn.082.0043

4. Hasan F, Shah AA, Hameed A. Industrial applications of microbial lipases. Enzyme Microb Technol. 2006 Jun;39(2):235-51, doi: 10.1016/j.enzmictec.2005.10.016

5. Price J, Nordblad M, Martel HH, Chrabas B, Wang H, Nielsen PM, Woodley JM. Scale-up of industrial biodiesel production to $40 \mathrm{~m}^{3}$ using a liquid lipase formulation. Biotechnol Bioeng. 2016 Jan;999(xxx), doi: 10.1002/bit.25936

6. Al-zuhair, S. Production of biodiesel by lipase-catalyzed trans esterification of vegetable oils. Biotechnol Prog. 2005 Set;21(5):1442-8, doi: 10.1021/bp050195k

7. Nerurkar M, Manasi J, Sujata P, Ravindra A. Application of Lipase from Marine Bacteria Bacillus sonorensis as an Additive in Detergent Formulation. J Surfact Deterg. 2013 May;16(3):435-43, doi: 10.1007/s11743-012-1434-0

8. Freire DMA, Castilho LR. Lipases em biocatálise. Rio de Janeiro (Rio de Janeiro): Editora Interciência; 2008. Capítulo 16, In: Bon EPS, Ferrara MA, Corvo ML. Enzimas em biotecnologia produção, aplicações e mercado; p. 506, ISBN: 9788571931893

9. Adrio JL, Demain AL. Microbial Enzymes: Tools for Biotechnological Processes. Biomolec. 2014 Feb;4(1):117-39, doi: 10.3390/biom4010117

10. Soares CMF. Otimização por planejamento experimental da imobilização de lipase em sílica de porosidade controlada na presença de estabilizantes [Dissertação]. Campinas (SP): Universidade Estadual de Campinas em Campinas; 2000. 121p.

11. Gupta RN, Gupta PR. Bacterial lipases: an overview of production, purification and biochemical properties. Appl Microbiol Biotechnol. 2004 Jun;64(6):763-81, doi: 10.1007/s00253-004-1568-8.

12. Tembhurkar VR, Kulkarni MB, Peshwe SA. Optimization of Lipase Production by Pseudomonas spp. in submerged batch process in shake flask culture. Sci Res Repot. 2012 Mar;2(1):46-50.

13. Treichel H, Sbardelotto M, Venturin B, Dall Agnol A, Mulinari J, Golunski SM, Baldoni DB, Bevilacqua CB, Jacques R JS, Vargas GDLP, Mossi AJ. Lipase Production from a newly Isolated Aspergillus Niger by Solid State Fermentation using Canola Cake as Substrate. Curr Biotechnol. 2016 Feb;5:1-7, doi: 10.2174/2211550105666151124193225

14. Cardenas F, Castro MS. Novel microbial lipases: catalytic activity in reactions in organic media. Enzyme Microb Technol. 2001 Feb;28(2-3): 145-54, doi: 10.1016/S0141-0229(00)00278-7

15. Gonçalves FAG. Produção e caracterização parcial de lipases com atividade de hidrólise e de síntese por fermentação em estado sólido de farelo de soja [Dissertação]. Belo Horizonte (MG): Universidade Federal de Minas Gerais em Belo Horizonte; 2007. 190p.

16. Dingle J, Reid WW, Solomons GL. The enzymatic degradation of pectin and other polysaccharides. II. Application of the "cup-plate" assay to the estimation of enzymes. J Sci Food Agr. 2006 Mar;4(3):149-55, doi: 10.1002/jsfa.2740040305

17. Hankin L, Anagnostakis SL. The use of solid media for detection of enzyme production by fungi. Mycol. 1975 May;67(3):597-607, doi: 10.2307/3758395 
18. Semionato S. Avaliação da atividade lipolítica de bactérias isoladas dos dispositivos de remoção de gordura da ETE-UFES [Dissertação]. Vitória (ES): Universidade Federal do Espírito Santo em Vitória; 2006. 82p.

19. Lock LL. Seleção de leveduras lipolíticas isoladas de bromélias e produção e caracterização de lipase bruta de Debaryomyces melissophilus BI81 [Dissertação]. Porto Alegre (RS): Universidade Federal do Rio Grande do Sul em Porto Alegre; 2007. 125p.

20. Bhavani M, Chowdary GV, David M, Archana G. Screening, Isolation and Biochemical Characterization of Novel Lipase Producing Bacteria from Soil Samples. Int J Biol Eng. (2012) Mar;2(2):18-22, doi:10.5923/j.ijbe.20120202.03.

21. Silva WOB, Mitidieri S, Schrank A, Vainstein MH. Production and extraction of an extracellular lipase from the entomopathogenic fungus Metarhizium anisopliae. Proc Biochem. 2005 Jan;40(1):321-26, doi:10.1016/j.procbio.2004.01.005

22. Falony, G.; Armas, J. C.; Mendoza, J. C. D.; Hernández, J. L. M. Production of Extracellular Lipase from Aspergillus niger by Solid-State Fermentation. Food Technol Biotechnol. 2006 Mar;44(2):23540.

23. Kumar D, Kumar L, Nagar S, Raina C, Parshad R, Gupta VK. Screening, isolation and production of lipase/esterase producing Bacillus sp. strain DVL2 and its potential evaluation in esterification and resolution reactions. Arch Appl Sci Res. 2012 Aug;4(4):1763-70. 